\title{
Optimization of a catalytic hydrogenation procedure of a prostaglandin intermediate by DOE methods
}

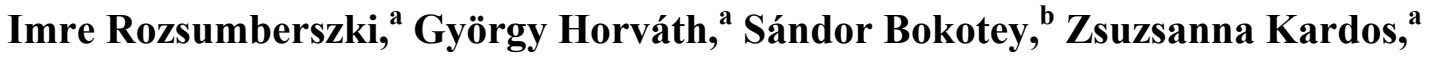 \\ Tibor Szabó, ${ }^{a}$ and Klara Osapay ${ }^{c}$ \\ ${ }^{a}$ PG Business Unit, Chinoin Ltd. - Sanofi-Synthelabo Group Budapest, \\ H-1045 Tó utca 1-5, Hungary, \\ ${ }^{b}$ Preclinical Development, Chinoin Ltd. - Sanofi-Synthelabo Group Budapest, \\ H-1045 Tó utca 1-5, Hungary, \\ ${ }^{c}$ Department of Pathology,University of California Irvine, CA 92697, USA
}

E-mail: imre.rozsumberszki@sanofi-synthelabo.com, zsuzsanna.kardos@sanofi-synthelabo.com

\section{Dedicated to Professor Sándor Antus on the occasion of his $60^{\text {th }}$ birthday}

(received 09 Dec 03; accepted 15 Jan 04; published on the web 25 Jan 04)

\begin{abstract}
An optimization procedure for the preparation of Beraprost key intermediate $\mathbf{2}$ is described. The catalytic hydrogenation of lactone $\mathbf{3}$ was optimized by Design of Experiment (DoE) methods for minimal Ullmann type side product formation. Experiments used a fractional factorial design method followed by a central composite design allowing optimization of a number of factors as well as statistical analysis of results. The response surface analysis showed that the rate of the side reaction, in a defined experimental area, can be described by a second-order polynomial equation in which the water content and the status of the catalyst are the major influences. The results confirm the mechanistic hypothesis of dimer production as a side reaction on the surface of the catalyst.
\end{abstract}

Keywords: Ullmann-type dimer, hydrogenation byproduct, catalytic hydrogenation, design of experiment, response surface analysis

\section{Introduction}

Prostanoids are biologically highly active compounds and are involved in the regulation of numerous physiological processes in mammalia. ${ }^{1}$ Beraprost (1) is a stabilized prostacycline derivative applied for the treatment of thrombosis and peripheral arterial occlusive disease. ${ }^{2}$ Acid $\mathbf{2}$ is the starting material for Beraprost synthesis (Scheme 1) and is required in kg scale. 

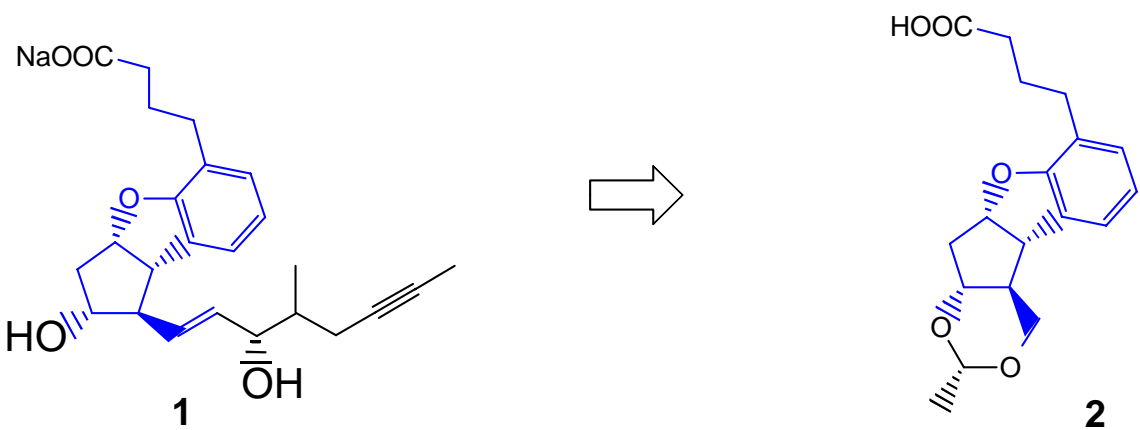

Scheme 1. (compounds are racemic, only one of the two enantiomers is shown).

The best known procedure for the preparation of acid $\mathbf{2}$ is the catalytic hydrogenation of lactone $\mathbf{3}$ in ethyl acetate in the presence of sodium acetate as a base for the neutralization of hydrogen bromide. ${ }^{3}$

According to preliminary studies, the reaction time in ethyl acetate was too long for our purposes. Use of tetrahydrofuran (THF) as a solvent resulted in a shorter reaction time and greater yield, but on the other hand, THF is highly flammable and dangerous together with pyrophoric catalysts. Therefore, optimization experiments on catalysts also were necessary. The base triethylamine proved to be more effective in neutralization of the released acid (Scheme 2) than the previously used sodium acetate. ${ }^{3}$ However, altered parameters led to the formation of a new side product, dimer 4 (up to 30\%). Appearance of this Ullmann type dimer decreased the yield and also made the crystallization of the product difficult.

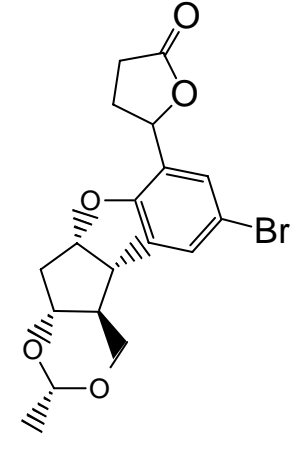

3

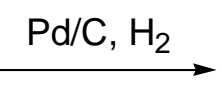

THF

Scheme 2. (compounds are racemic, only one of the two enantiomers is shown).

The purpose of the research presented in this paper is to discover the reason for the side reaction in order to optimize the procedure to achieve maximum yield of acid 2 .

The structure elucidation of dimer 4 side product was done on the bases of NMR and $a b$ initio calculation. In comparison to the ${ }^{1} \mathrm{H}$ and ${ }^{13} \mathrm{C}$ NMR spectra of acid 2 , the aromatic region of the dimer shows signals corresponding to only two aromatic protons. In the ${ }^{1} \mathrm{H}$ NMR spectra at 
room temperature all signals of the side product are broadened, but their chemical shifts are very similar to the monomer, acid 2. Details of the structural studies related to the dimeric side product are described in the experimental section.

The classical Ullmann reaction applies copper bronze as a reducing agent at elevated temperatures. ${ }^{4-6}$ Later methods used other metals, for example nickel catalyst, generated by coreductants. $^{7-9}$ Palladium has also been shown to catalyze aryl halide homocoupling under elevated reaction temperatures in the presence of a reducing agent under both transfer ${ }^{10-12}$ and catalytic hydrogenation conditions. ${ }^{13}$ The transfer type process is discussed in more detail in the literature and the following parameters promote the formation of Ullmann dimers: phase transfer conditions, presence of strong bases, elevation of temperature and increasing amounts of catalyst. $^{10-12}$

\section{Results and Discussion}

A systematic design of experiment (DoE) was performed in order to evaluate and optimize the affecting factors such as solvent volume, pretreatment and water content status of the catalyst, amount of the catalyst, the base (triethylamine), the auxiliary agent ( $\mathrm{HBr}$ salt of triethylamine), and the water content. Conducting the reaction at lower temperature ranges might result in lower dimer side product, but it would also decrease the yield of acid 2, so, we kept the temperature constant $\left(40{ }^{\circ} \mathrm{C}\right)$ during our experiments. We applied hydrogen gas as a reducing agent at constant pressure and rate of agitation.

A fractional factorial experiment $\left(2^{6-2}\right)$ was designed by setting six parameters at two levels. The percent of the peak area of the dimer side product compared to that of the main product as measured by high pressure liquid chromatography (HPLC) was the dependent variable (Table 1). The status of the catalyst $\left(\mathrm{x}_{2}\right)$ is coded -1 when no pre-hydrogenation was applied and +1 when pre-hydrogenation of the catalyst was employed by Method B for 30 minutes. The program Statistica (Version 6) computed the combination of the factor settings. Instead of full factorial design fractional factorials were used, that meant less experiment runs, and interaction effects were "sacrificed" so that main effects were still computed correctly. In the Pareto chart (Figure 1) analysis of variance (ANOVA) effect estimates are sorted from the largest absolute value to the smallest absolute value. While the amount of triethylamine, its salt and the catalyst have negligible effects on dimer formation, water content and the volume of the solvent have significant influence on the side reaction. In addition, pre-hydrogenation of the catalyst also influences the outcome of the reaction. The criterion for statistical significance, alpha is set to 0.05 (dashed line in Figure 1).

Based on the results of the fractional factorial method and analysis, three parameters were chosen for optimization by a central composite design. The parameter settings (Table 2) were similar to the ones in the factorial design except with some additions. Five combinations of the water content $\left(\mathrm{x}_{2}\right)$ and pretreatment status of the catalyst $\left(\mathrm{x}_{3}\right)$ were used (Table 3$)$. Central points 
were added to make estimates of quadratic effects. Prediction of conditions to achieve minimum side product formation was determined by fitting an equation to the observed responses based on the independent $x$ variables. The response surface was analyzed to find the levels of the $x$ variables, which simultaneously produced the most desirable predicted responses on the $y$ variable.

ANOVA resulted in the Pareto graph of the standardized estimated effects (Figure 2). It clearly shows that water content and pre-hydrogenation of the catalyst are the parameters that are significant variables that influence the outcome of the reaction.

The response surface equation for standardized factor levels is of second order:

$$
\begin{aligned}
y^{\prime} \text { estimated }= & 11.814-0.636 * x_{1}+6.112 * x_{2}-2.821 * x_{3}+0.376 * x_{1}{ }^{2}+0.912 * x_{2}{ }^{2} \\
& -0.377 * x_{3}{ }^{2}-0.044 * x_{1} * x_{2}+0.819 * x_{1} * x_{3}-0.716 * x_{2} * x 3
\end{aligned}
$$

The regression coefficients of the equation are effect estimates of the parameters that mean how much improvement can be expected in the dependent variable if the setting of the factor changes from low to high setting. The response surface equation for the original (untransformed) factor settings (Table 4) has a simpler form because the regression coefficient is negligible for some of the second order members:

$$
y_{\text {estimated }}=16,407-0,526 * x_{1}+0,047 * x_{2}-1,58 * x_{3}+0,004 * x_{1}{ }^{2}-0,377 * x_{3}{ }^{2}+0,082 * x 1 * x 3
$$

Because the metric for the different factors is no longer compatible, the magnitudes of the regression coefficients are not compatible either. However, equation 2 is useful in making predictions for the dependent variable.

The normal probability plot of the estimates also helps to quickly sort out the important factors (Figure 3). In this plot the effects are ranked, and then a normal $z$ score is computed based on the assumption that the estimates are normally distributed. This $\mathrm{z}$ score is plotted on the Y-axis against the observed estimates. Small effects that are due to random noise will be distributed with a mean of 0 , and will be plotted along a reference line in the graph. Significant "real" effects ( $x_{2}$ and $x_{3}$ in Figure 3 ) that don't fall on the line do not "belong" to the distribution of random noise effects.

For each independent variable, a separate equation also was fitted to the observed responses. Figure 4 consists of a prediction profile for the biaryl side product formation, a series of graphs, one for each parameter. While other independent variables are kept at a constant value, the prediction profiles show which levels of the predictor variables produce the most desirable response. We have calculated the values of these predictor variables at three values of the response surface. The lowest value is 2.17 , the medium value is 15.35 , and the highest value is 28.54. From the graphs of Figure 4, we can predict the values of our independent variables that will produce the most desirable minimum of the side product formation. Table 5 lists the critical values of these factors that will determine the optimum level of the independent variable, the success of the reaction. 
Fitted overall response of the biaryl side product formation can best be summarized in response surface plots and contour plots as shown in Figures 5, 6, and 7. The steepest fall of the surface is seen with the change of the water content that is in agreement to the Pareto graph and the probability plot produced by the statistical analysis of the data. Conditions of the reaction when originally performed compared to the optimized conditions are displayed in Table 8 . The yield of the reaction significantly increased from $70 \pm 10 \%$ to $90 \pm 10 \%$, while the percent of the biaryl side product decreased from $5-30 \%$ to $0-3 \%$.

Our results suggest the following hypothesis of the reaction mechanism. If we suppose that hydrogen molecules are adsorbed on the surface of the catalyst and aryl halide molecules are near, there is a minimum number of $\mathrm{H}$ atoms that should be present to react with the aryl halide molecules. If there are too many water molecules present, the small water molecules hinder the adsorption of the hydrogen on the catalyst surface, and aryl - aryl dimerization is more probable. Pre-hydrogenation of the catalyst helps to provide more hydrogen and avoid adsorption of other small molecules.

Table 1. $2^{(6-2)}$ Type design and results

\begin{tabular}{|c|c|c|c|c|c|c|c|}
\hline \multirow{2}{*}{$\begin{array}{l}\text { Standard } \\
\text { Run }\end{array}$} & \multicolumn{7}{|c|}{ Design: $2^{* *}$ design } \\
\hline & $\begin{array}{l}\text { Solvent } \\
(\mathrm{THF})(\mathrm{ml}) \\
(\mathrm{X} 1)\end{array}$ & $\begin{array}{l}\text { Catalyst } \\
\text { Status } \\
(\mathrm{X} 2)\end{array}$ & $\begin{array}{l}\text { Catalyst } \\
\text { Amount (g) } \\
\text { (X3) }\end{array}$ & $\begin{array}{l}\mathrm{Et}_{3} \mathrm{~N} \text { base } \\
\text { Volume }(\mu \mathrm{l}) \\
(\mathrm{X} 4)\end{array}$ & $\begin{array}{l}\text { Water } \\
\text { content }(\mu \mathrm{l}) \\
(\mathrm{X} 5)\end{array}$ & $\begin{array}{l}\mathrm{Et}_{3} \mathrm{~N} \cdot \mathrm{HBr} \\
\text { Amount } \\
(\mathrm{mg}) \\
(\mathrm{X} 6)\end{array}$ & $\begin{array}{l}\text { Biaryl } \\
\text { Side product } \\
\text { (HPLC area \%) }\end{array}$ \\
\hline 1 & 20 & -1 & 0.050 & 100 & 10 & 40 & 4.41 \\
\hline 2 & 40 & -1 & 0.050 & 100 & 200 & 40 & 10.47 \\
\hline 3 & 20 & 1 & 0.050 & 100 & 200 & 300 & 10.14 \\
\hline 4 & 40 & 1 & 0.050 & 100 & 10 & 300 & 1.92 \\
\hline 5 & 20 & -1 & 0.250 & 100 & 200 & 300 & 17.84 \\
\hline 6 & 40 & -1 & 0.250 & 100 & 10 & 300 & 5.36 \\
\hline 7 & 20 & 1 & 0.250 & 100 & 10 & 40 & 5.09 \\
\hline 8 & 40 & 1 & 0.250 & 100 & 200 & 40 & 5.72 \\
\hline 9 & 20 & -1 & 0.050 & 1500 & 10 & 300 & 5.21 \\
\hline 10 & 40 & -1 & 0.050 & 1500 & 200 & 300 & 10.13 \\
\hline 11 & 20 & 1 & 0.050 & 1500 & 200 & 40 & 18.05 \\
\hline 12 & 40 & 1 & 0.050 & 1500 & 10 & 40 & 5.28 \\
\hline 13 & 20 & -1 & 0.250 & 1500 & 200 & 40 & 16.18 \\
\hline 14 & 40 & -1 & 0.250 & 1500 & 10 & 40 & 4.93 \\
\hline 15 & 20 & 1 & 0.250 & 1500 & 10 & 300 & 5.12 \\
\hline 16 & 40 & 1 & 0.250 & 1500 & 200 & 300 & 5.33 \\
\hline
\end{tabular}

$\mathrm{X}_{2}$ : -1 pre-hydrogenation, 1 no pre-hydrogenation, $\mathrm{X}_{3}$ : g catalyst/ $0.1 \mathrm{~g}$ compound 3. 


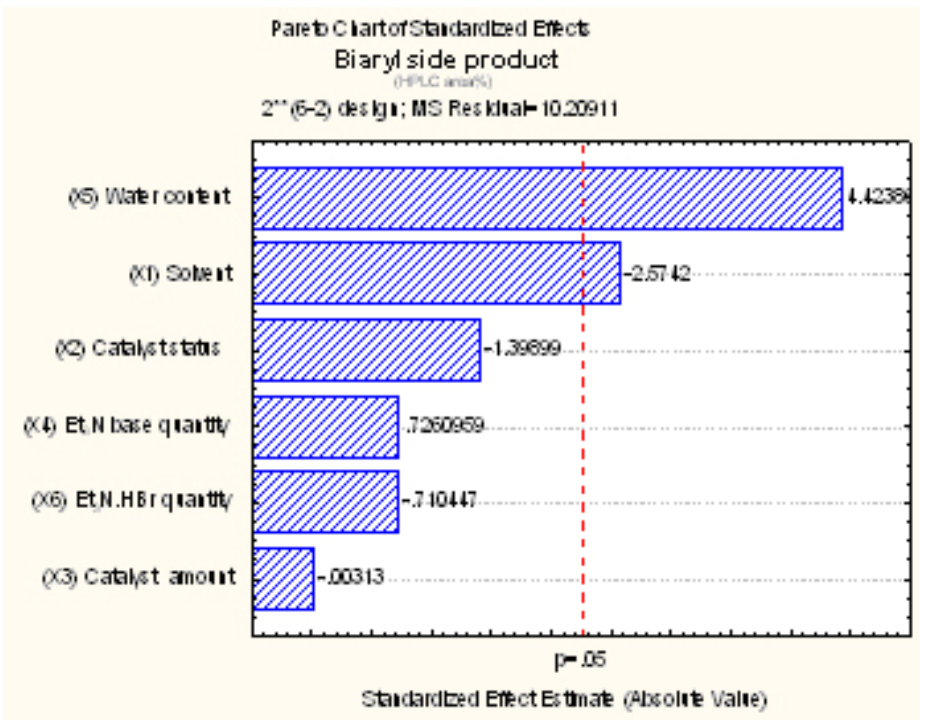

Figure 1. Pareto Graph of standardized estimated effects.

Table 2. $2^{3}$ type central composite design and results

\begin{tabular}{lllll}
\hline Standard Run & \multicolumn{4}{l}{$2^{* *}(3)$ central composite, $\mathrm{nc}=8 \mathrm{~ns}=6 \mathrm{n} 0=2$ Runs $=16$} \\
& $\begin{array}{l}\text { Solvent }(\mathrm{ml}) \\
(\mathrm{X} 1)\end{array}$ & Water content $(\mu \mathrm{l})$ & Catalyst & Biaryl \\
& & $(\mathrm{X} 2)$ & Status & Side product \\
& & & $(\mathrm{X} 3)$ & (HPLC area $\%)(\mathrm{X} 4)$ \\
\hline 1 & 20.00 & 300.00 & 2.00 & 25.00 \\
2 & 20.00 & 300.00 & 4.00 & 10.75 \\
3 & 20.00 & 100.00 & 2.00 & 10.45 \\
4 & 20.00 & 100.00 & 4.00 & 5.47 \\
5 & 40.00 & 300.00 & 2.00 & 18.25 \\
6 & 40.00 & 300.00 & 4.00 & 13.68 \\
7 & 40.00 & 100.00 & 2.00 & 10.28 \\
8 & 40.00 & 100.00 & 4.00 & 2.17 \\
9 & 13.18 & 200.00 & 3.00 & 14.31 \\
10 & 46.82 & 200.00 & 3.00 & 13.48 \\
11 & 30.00 & 368.18 & 3.00 & 28.54 \\
12 & 30.00 & 31.82 & 3.00 & 2.28 \\
13 & 30.00 & 200.00 & 1.32 & 13.73 \\
14 & 30.00 & 200.00 & 4.68 & 9.80 \\
15 & 30.00 & 200.00 & 3.00 & 11.58 \\
16 & 30.00 & 200.00 & 3.00 & 11.7 \\
\hline
\end{tabular}


Table 3. Code for $\mathrm{Pd} / \mathrm{C}(10 \% \mathrm{Pd})$ catalyst water content and pretreatment status

Code of catalyst status

$<2$
2
3
4
$>4$

\section{Water content}

$80 \%$

$60 \%$

$50 \%$

$3 \%$

$3 \%$
Pretreatment

no pre-hydrogenation

no pre-hydrogenation

no pre-hydrogenation

no pre-hydrogenation

Pre-hydrogenation for 30 minutes by Method B

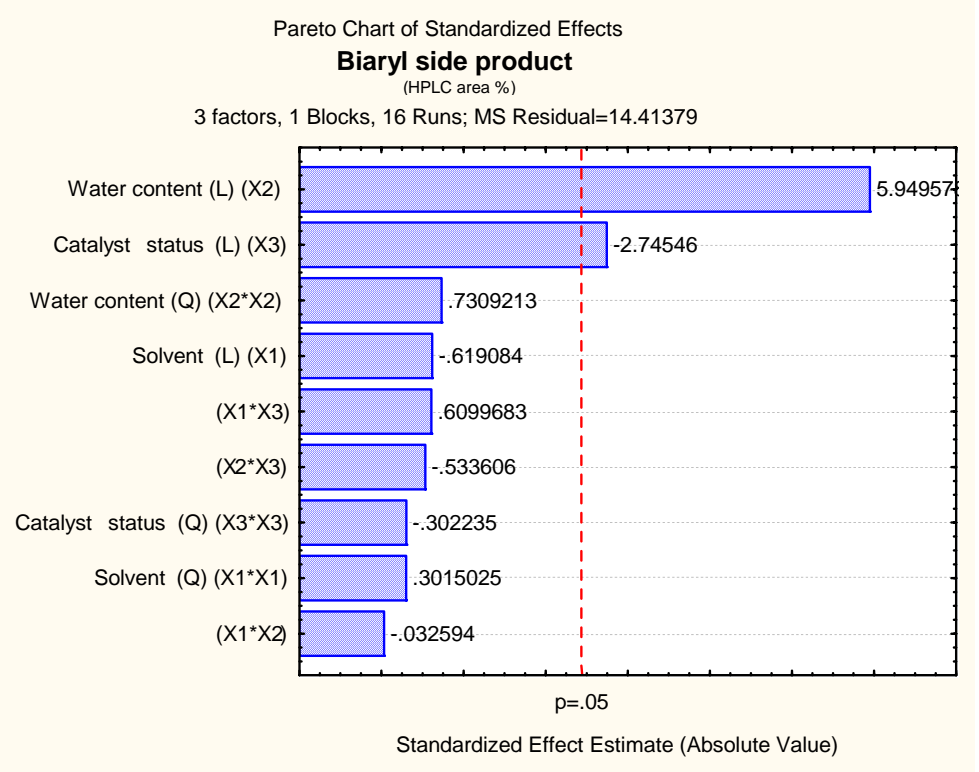

Figure 2. Pareto Graph of standardized estimated effects.

Table 4. Regression coefficients for the factors in $2^{3}$ type central composite design

\begin{tabular}{|c|c|c|c|c|c|c|}
\hline \multirow[t]{3}{*}{ Factor } & \multicolumn{6}{|c|}{ Regr. Coefficients; Var.: Biaryl side product (HPLC area \%); R-sqr=.88236 } \\
\hline & Regressn & Std. Err. & $\mathrm{t}(6)$ & $\mathrm{p}$ & $-95 . \%$ & $+95 . \%$ \\
\hline & \multicolumn{4}{|l|}{ Coeff. } & Cnf. Limit & Cnf. Limit \\
\hline Mean/Interc. & 16.407 & 25.996 & 0.631 & 0.551 & -47.203 & 80.017 \\
\hline Solvent (ml) (L) (X1) & -0.526 & 0.897 & -0.586 & 0.579 & -2.721 & 1.669 \\
\hline Solvent (ml) (Q) $(\mathrm{X} 1 * \mathrm{X} 1)$ & 0.004 & 0.012 & 0.302 & 0.773 & -0.027 & 0.034 \\
\hline Water content $(\mu 1)(\mathrm{L})(\mathrm{X} 2)$ & 0.047 & 0.076 & 0.621 & 0.557 & -0.140 & 0.234 \\
\hline Water content $(\mu \mathrm{l})(\mathrm{Q})(\mathrm{X} 2 * \mathrm{X} 2)$ & 0.000 & 0.000 & 0.731 & 0.492 & -0.000 & 0.000 \\
\hline Catalyst status (L) (X3) & -1.582 & 8.972 & -0.176 & 0.866 & -23.535 & 20.370 \\
\hline Catalyst status (Q) (X3*X3) & -0.377 & 1.247 & -0.302 & 0.773 & -3.429 & 2.675 \\
\hline$(\mathrm{X} 1 * \mathrm{X} 2)$ & -0.000 & 0.001 & -0.033 & 0.975 & -0.003 & 0.003 \\
\hline$(\mathrm{X} 1 * \mathrm{X} 3)$ & 0.082 & 0.134 & 0.610 & 0.564 & -0.247 & 0.410 \\
\hline$(\mathrm{X} 2 * \mathrm{X} 3)$ & -0.007 & 0.013 & -0.534 & 0.613 & -0.040 & 0.026 \\
\hline
\end{tabular}




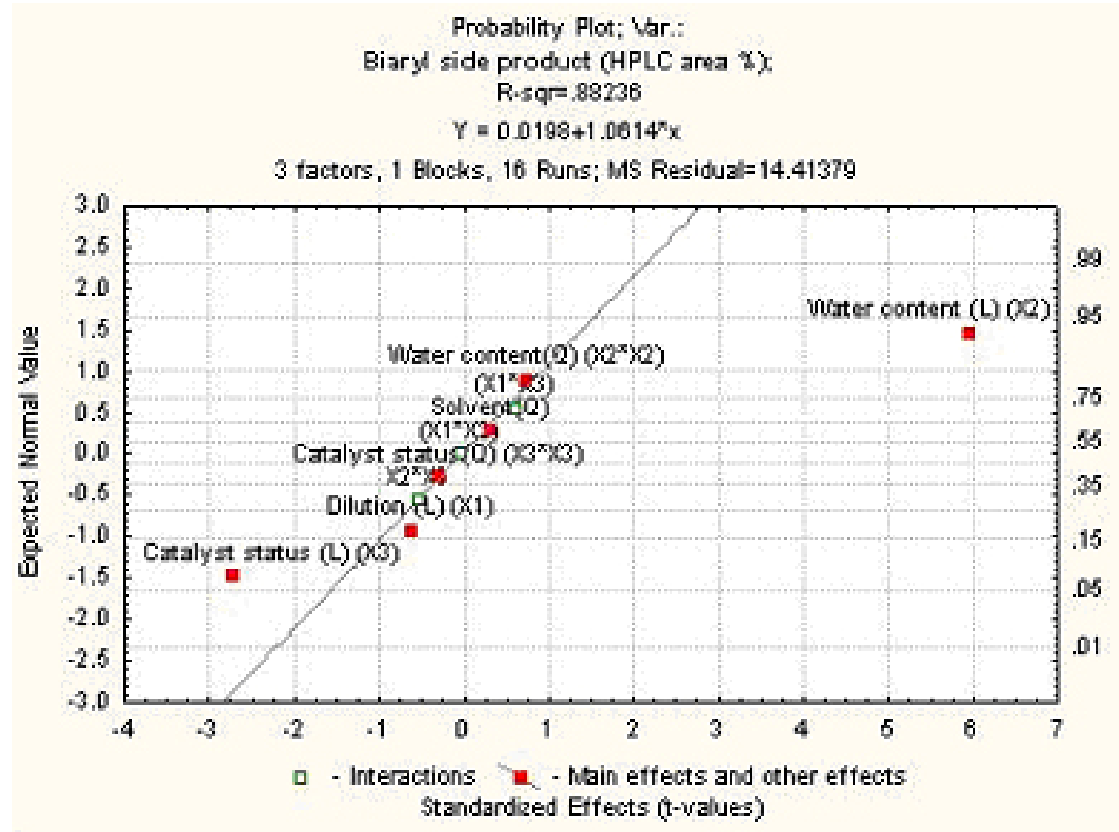

Figure 3. Normal probability plot of main effects and interactions.

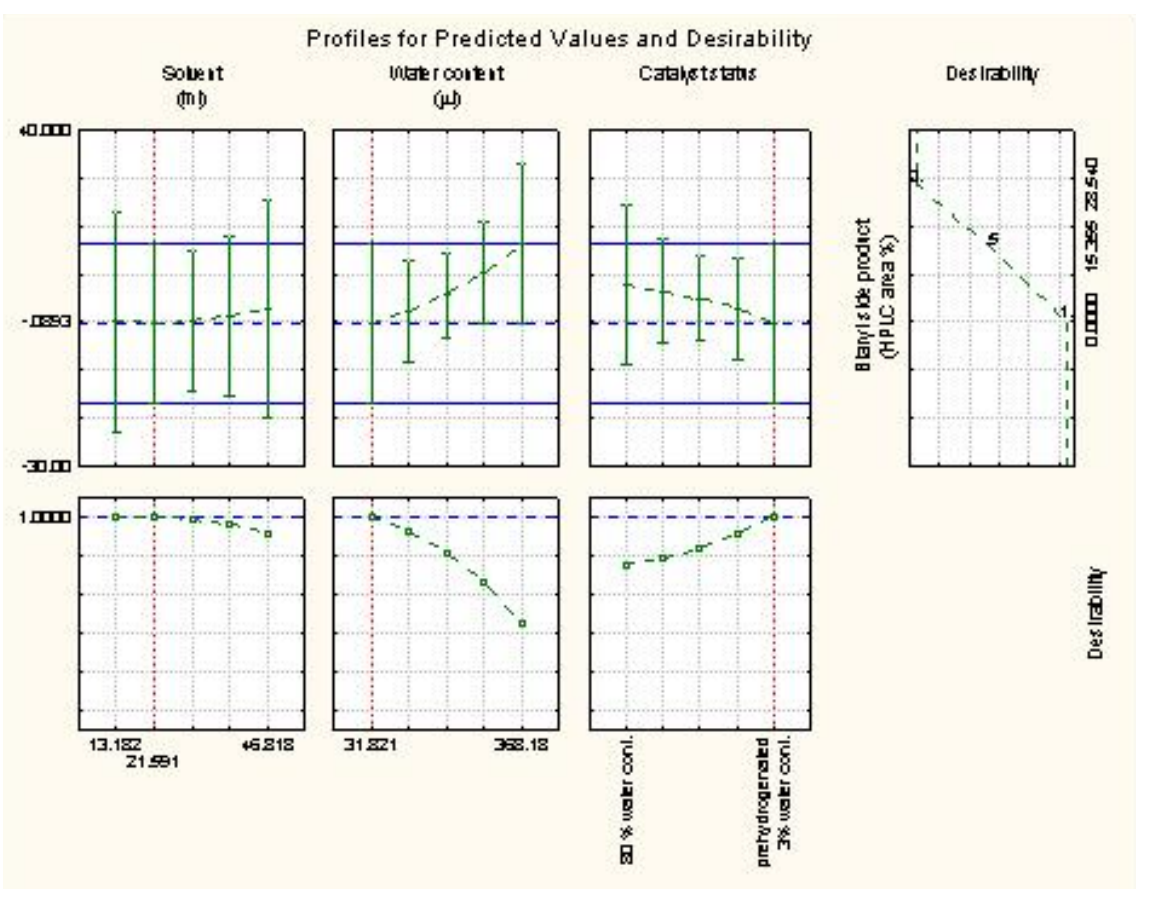

Figure 4. Optimum searching process for factors. 
Table 5. Predicted factor levels for the minimum dimer formation

\begin{tabular}{ll}
\hline Solvent (THF, ml) & 21.681 \\
\hline Catalyst & Pre-hydrogenated Johnson-Matthey \\
& JM-87L dry (water. 3\%) \\
Water $(\mu \mathrm{l})$ & $<31.82$ \\
\hline
\end{tabular}

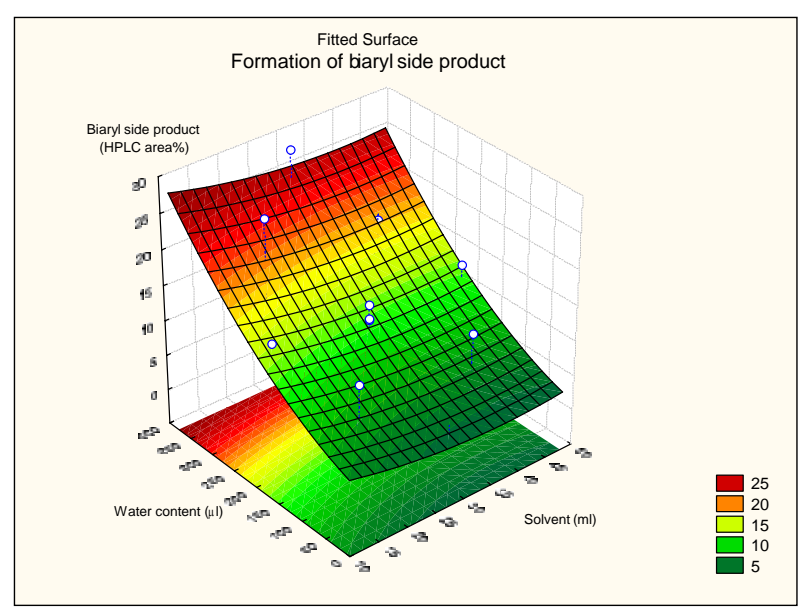

Figure 5. The effect of varying water content and solvent volume on biaryl side product formation when the catalyst was held at optimum status.

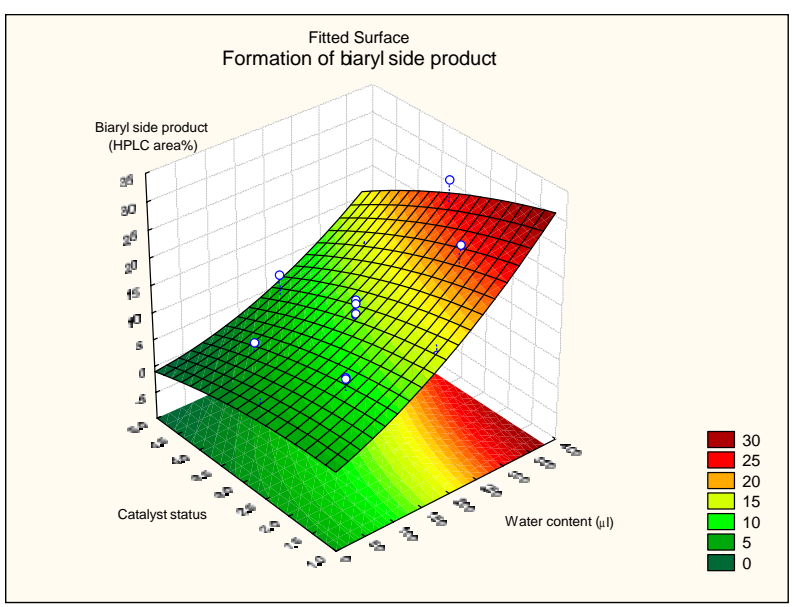

Figure 6. The effect of varying water content and catalyst status on biaryl side product formation when the solvent volume was held at optimum.

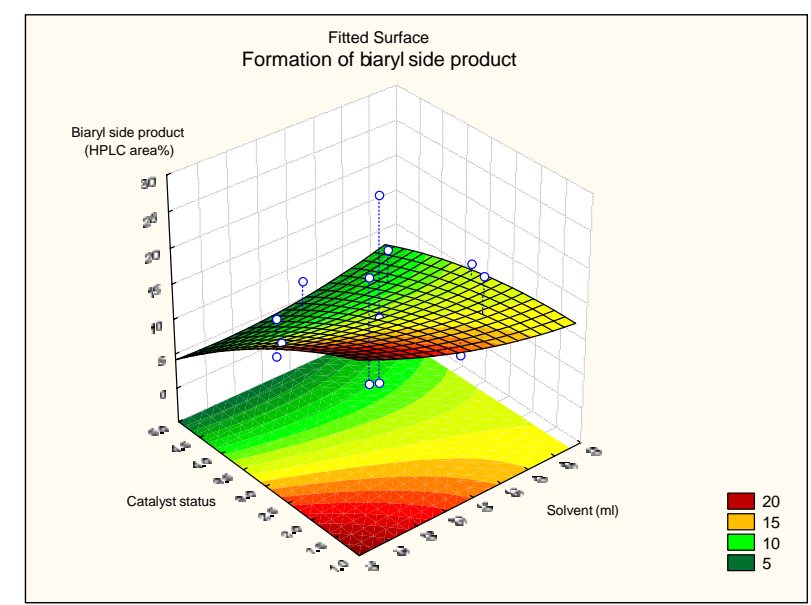

Figure 7. The effect of varying catalyst status and solvent volume on biaryl side product formation when the water content was held at optimum. 
Table 6. Result of optimization

\begin{tabular}{lcc}
\hline & Process before optimization & Optimized process \\
\hline Lactone (2) $(\mathrm{g})$ & 0.1 & 0.1 \\
Hydrogen pressure (bar) & 0.05 & 0.05 \\
Stirring speed (rpm) & 900 & 900 \\
Temperature $\left({ }^{\circ} \mathrm{C}\right)$ & 40 & 40 \\
Solvent (THF, ml) & 20 & 21.7 \\
Water ( 1$)$ & 60 & $<30$ \\
Catalyst quantity (g) & 0.05 & 0.05 \\
Catalyst status & $\mathrm{Pd} / \mathrm{C}(10 \% \mathrm{Pd}$ and $60 \%$ water $)$ & $\mathrm{Pd} / \mathrm{C}(10 \% \mathrm{Pd}$ and 3\% water $)$ \\
Base (Triethylamine, ml) & 0.107 & pre-hydrogenated \\
Yield (\%) & $70 \pm 10$ & 0.107 \\
Biaryl side product formation & $5-30$ & $90 \pm 10$ \\
$(\%)$ & & $0-3$ \\
\hline
\end{tabular}

\section{Conclusions}

Reaction conditions for acid 2, the key intermediate in Beraprost synthesis were optimized to decrease the Ullmann type dimer formation. While keeping temperature and pressure constant, water content, and pretreatment of the catalyst were identified as the most significant factors influencing the rate of the side reaction and the yield of the product. Decreasing water content in the reaction mixture resulted in lower dimer formation. Prehydrogenation of the catalyst was also found to be important. This effect can be explained by the higher palladium hydride concentration at the surface of the catalyst that is beneficial for the formation of the desired product with less probability of side product formation.

The optimized synthesis (see Table 6) was performed in a pilot plant scale, and the yield and impurity profile supported the results of the design of experiment.

\section{Experimental Section}

General Procedures. HPLC analysis performed on Waters HPLC 600, analytical column was

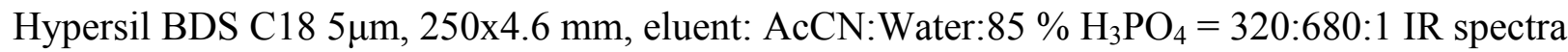
were recorded on a Bruker IFS-28 IR instrument. 
The ${ }^{1} \mathrm{H}$ and ${ }^{13} \mathrm{C}$ NMR spectra were recorded on a Bruker DRX-400 MHz $\left({ }^{1} \mathrm{H} 400.13 \mathrm{MHz}\right.$; $\left.{ }^{13} \mathrm{C}, 100.61 \mathrm{MHz}\right)$ spectrometer using $\mathrm{CDCl}_{3}: \mathrm{CD}_{3} \mathrm{OD}(1: 1)$ and $\mathrm{C}_{2} \mathrm{D}_{2} \mathrm{Cl}_{4}$ solvents. Chemical shifts are reported relative to tetramethylsilane (TMS). $\mathrm{C}_{2} \mathrm{D}_{2} \mathrm{Cl}_{4}$ was purchased from Aldrich, $\mathrm{CDCl}_{3}, \mathrm{CD}_{3} \mathrm{OD}$ and TMS from Merck.

All ab-initio calculations were carried out at Hartree-Fock level by using RHF/321 basis set.

Starting materials were purchased form Aldrich Chemical Company unless otherwise noted. Silica gel $60 \mathrm{~F}_{254}$ (Merck) plates were used for TLC. Silica gel (40-63 $\mu \mathrm{m}$, Merck) was used for column chromatography.

Chinoin catalyst was prepared in house, Johnson-Matthey catalyst was a commercial grade and used without further purification.

\section{General procedures for preparation of acid 2}

Method A (without pre-hydrogenation of the catalyst)

A mixture of lactone $2(0.1 \mathrm{~g} 0.253 \mathrm{mmol})$ and $\mathrm{Pd} / \mathrm{C}$, was stirred at room temperature in THF for 5 minutes and triethylamine was added. The mixture was hydrogenated under 0.05 bar pressure at $40^{\circ} \mathrm{C}$ for 5 hours. The catalyst was filtered and washed with THF. Filtrate and washings were combined and the solvent was evaporated. The residue was dissolved in toluene $(2.5 \mathrm{ml})$ and the product was extracted with $1 \mathrm{M} \mathrm{NaHCO}_{3}(3 \times 2 \mathrm{ml})$.

The aqueous solution was acidified by the addition of $1.5 \mathrm{M} \mathrm{NaHSO}_{4}$ solution $(6 \mathrm{ml})$ and the precipitated product was filtered and washed with water $(3 \times 2 \mathrm{ml})$. Crystals were dried at room temperature.

\section{Method B (with pre-hydrogenation of the catalyst)}

$\mathrm{Pd} / \mathrm{C}$ was suspended in THF and hydrogenated under 0.05 bar pressure for 30 minutes. The following steps were identical to those described in method A.

\section{Method C (with triethylamine salt)}

Triethylamine was stirred in THF and an equivalent amount of $47 \%$ aqueous hydrogen bromide was added dropwise. The mixture was cooled to $25^{\circ} \mathrm{C}$. The following steps were identical to those of method A.

\section{4,4a,4b,9a,10,10a-Hexahydro-2-methyl-1,3-dioxino [5',4':3,4]cyclopenta[1,2-b]benzofuran-}

8-butanoic acid (2). Colorless crystals, $\mathrm{mp}: 136.3-144.6^{\circ} \mathrm{C}$ (from water). Analysis calculated for $\mathrm{C}_{18} \mathrm{H}_{22} \mathrm{O}_{5}$ (318.36): C, 67.91; H, $6.96 \%$. Found: C, 67.75; H, $7.09 \%$.IR (KBr) 2947 (br, OH), $1704(\mathrm{C}=\mathrm{O}), 1597$ (aromatic) $\mathrm{cm}^{-1} .{ }^{1} \mathrm{H}$ NMR, $\delta_{\mathrm{H}}\left(\mathrm{CDCl}_{3}: \mathrm{CD}_{3} \mathrm{OD}\right): 1.30(\mathrm{~d}, 3 \mathrm{H}, J=5.1 \mathrm{~Hz}, 18-$ $\mathrm{H}), 1.71(\mathrm{qd}, 1 \mathrm{H}, J=10.8 \mathrm{~Hz}, J=4.4 \mathrm{~Hz}, 12-\mathrm{H}), 1.8-2.0\left(\mathrm{~m}, 3 \mathrm{H}, 3-\mathrm{H}_{2}, 10-\mathrm{H}_{\mathrm{b}}\right), 2.28(\mathrm{t}, 2 \mathrm{H}, J=$ $\left.7.4 \mathrm{~Hz}, 2-\mathrm{H}_{2}\right), 2.59\left(\mathrm{t}, 2 \mathrm{H}, J=7.4 \mathrm{~Hz}, 4-\mathrm{H}_{2}\right), 2.71$ (ddd, $1 \mathrm{H}, J=12.3 \mathrm{~Hz}, J=7.2 \mathrm{~Hz}, J=6.5 \mathrm{~Hz}$, $10-\mathrm{H}_{\mathrm{a}}$ ), $3.18(\mathrm{dd}, 1 \mathrm{H}, J=10.9 \mathrm{~Hz}, J=10.8 \mathrm{~Hz}, 8-\mathrm{H}), 3.47$ (ddd, $1 \mathrm{H}, J=11.6 \mathrm{~Hz}, J=10.8 \mathrm{~Hz}, J$ $=6.3 \mathrm{~Hz}, 11-\mathrm{H}), 3.76\left(\mathrm{t}, 1 \mathrm{H}, J=10.8 \mathrm{~Hz}, 13-\mathrm{H}_{\mathrm{ax}}\right), 4.36(\mathrm{dd}, 1 \mathrm{H}, J=10.8 \mathrm{~Hz}, J=4.4 \mathrm{~Hz}, 13-$ $\mathrm{H}_{\mathrm{eq}}$ ), $4.74(\mathrm{q}, 1 \mathrm{H}, J=5.1 \mathrm{~Hz}, 17-\mathrm{H}), 5.09$ (ddd, $\left.1 \mathrm{H}, J=10.9 \mathrm{~Hz}, J=7.2 \mathrm{~Hz}, J=5.9 \mathrm{~Hz}, 9-\mathrm{H}\right)$, $6.75(\mathrm{t}, 1 \mathrm{H}, J=7.4 \mathrm{~Hz}, 15-\mathrm{H}), 6.9-7.0(\mathrm{~m}, 2 \mathrm{H}, 14,16-\mathrm{H})$. 
${ }^{1} \mathrm{H}$ NMR, $\delta_{\mathrm{H}}\left(\mathrm{C}_{2} \mathrm{D}_{2} \mathrm{Cl}_{4}\right): 1.35(\mathrm{~d}, 3 \mathrm{H}, J=5.0 \mathrm{~Hz}, 18-\mathrm{H}), 1.82(\mathrm{qd}, 1 \mathrm{H}, J=10.8 \mathrm{~Hz}, J=4.2 \mathrm{~Hz}$, $12-\mathrm{H}), 1.9-2.0\left(\mathrm{~m}, 3 \mathrm{H}, 3-\mathrm{H}_{2}, 10-\mathrm{H}_{\mathrm{b}}\right), 2.37\left(\mathrm{t}, 2 \mathrm{H}, J=7.5 \mathrm{~Hz}, 2-\mathrm{H}_{2}\right), 2.61(\mathrm{t}, 2 \mathrm{H}, J=7.4 \mathrm{~Hz}, 4-$ $\left.\mathrm{H}_{2}\right), 2.73\left(\mathrm{ddd}, 1 \mathrm{H}, J=12.6 \mathrm{~Hz}, J=7.1 \mathrm{~Hz}, J=6.3 \mathrm{~Hz}, 10-\mathrm{H}_{\mathrm{a}}\right), 3.18(\mathrm{dd}, 1 \mathrm{H}, J=10.9 \mathrm{~Hz}, J=$ $9.0 \mathrm{~Hz}, 8-\mathrm{H}), 3.41(\mathrm{ddd}, 1 \mathrm{H}, J=11.6 \mathrm{~Hz}, J=10.8 \mathrm{~Hz}, J=6.3 \mathrm{~Hz}, 11-\mathrm{H}), 3.71$ (t, $1 \mathrm{H}, J=10.8$ $\left.\mathrm{Hz}, 13-\mathrm{H}_{\mathrm{ax}}\right), 4.36$ (dd, $\left.1 \mathrm{H}, J=10.8 \mathrm{~Hz}, J=4.2 \mathrm{~Hz}, 13-\mathrm{H}_{\mathrm{eq}}\right), 4.71$ (q, $\left.1 \mathrm{H}, J=5.0 \mathrm{~Hz}, 17-\mathrm{H}\right), 5.09$ (ddd, $1 \mathrm{H}, J=10.9 \mathrm{~Hz}, J=7.1 \mathrm{~Hz}, J=6.0 \mathrm{~Hz}, 9-\mathrm{H}), 6.78$ (t, $1 \mathrm{H}, J=7.6 \mathrm{~Hz}, 15-\mathrm{H}), 6.9-7.0$ (m, $2 \mathrm{H}, 14,16-\mathrm{H})$.

${ }^{13} \mathrm{C}$ NMR, $\delta_{\mathrm{C}}\left(\mathrm{C}_{2} \mathrm{D}_{2} \mathrm{Cl}_{4}\right): 20.6(\mathrm{C}-18), 24.2(\mathrm{C}-3), 28.8,33.1$ (C-2;C-4), $37.8(\mathrm{C}-10), 45.0(\mathrm{C}-12)$, 48.0 (C-8), 70.5 (C-13), 79.3 (C-11), 83.4 (C-9), 99.4 (C-17), 120.4 (C-15), 121.7 (C-16), 123.2, 128.3 (C-5; C-7), 128.8 (C-14), 157.0 (C-6), 179.3 (C-1).

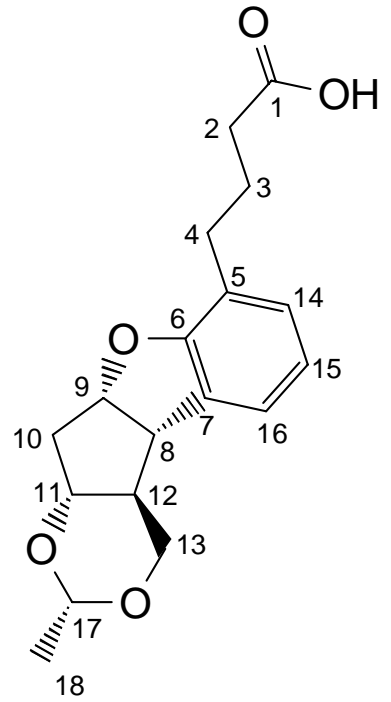

2

(compound is racemic, only one of the two enantiomers is shown)

\section{6,6'-Bis $\left[\left(4,4 a, 4 b, 9 a, 10,10 a-h e x a h y d r o-2-m e t h y l-1,3-d i o x i n o\left[5^{\prime}, 4^{\prime}: 3,4\right]\right.\right.$ cyclopenta}

[1,2-b]benzofuran-8-butanoic acid] (4). Dimer 4 was purified by silica gel column chromatography using methyl tert-butyl ether: methanol $(8: 1)$ as eluent to give a pale yellow oil. Analysis calculated for $\mathrm{C}_{36} \mathrm{H}_{42} \mathrm{O}_{10}$ (634.72): $\mathrm{C}, 68.12 ; \mathrm{H}, 6.67 \%$. Found: $\mathrm{C}, 67.98 ; \mathrm{H}, 6.72 \%$. IR (KBr) 2937 (br, OH), $1714(\mathrm{C}=\mathrm{O}), 1560$ (aromatic) $\mathrm{cm}^{-1}$.

${ }^{1} \mathrm{H}$ NMR, $\delta_{\mathrm{H}}\left(\mathrm{CDCl}_{3}: \mathrm{CD}_{3} \mathrm{OD}\right.$, all signals are broad): $1.30\left(6 \mathrm{H}, 18,18^{\prime}-\mathrm{H}\right), 1.77\left(2 \mathrm{H}, 12,12^{\prime}-\mathrm{H}\right)$, 1.8-2.0 (6H, 3,3'- $\left.\mathrm{H}_{2}, 10,10^{\prime}-\mathrm{H}_{\mathrm{b}}\right), 2.24\left(4 \mathrm{H}, 2,2^{\prime}-\mathrm{H}_{2}\right), 2.59\left(4 \mathrm{H}, 4,4^{\prime}-\mathrm{H}_{2}\right), 2.68\left(2 \mathrm{H}, 10,10^{\prime}-\mathrm{H}_{\mathrm{a}}\right)$, $3.17\left(2 \mathrm{H}, 8,8^{\prime}-\mathrm{H}\right), 3.46\left(2 \mathrm{H}, 11,11^{\prime}-\mathrm{H}\right), 3.76\left(2 \mathrm{H}, 13,13^{\prime}-\mathrm{H}_{\mathrm{ax}}\right), 4.37\left(2 \mathrm{H}, 13,13^{\prime}-\mathrm{H}_{\mathrm{eq}}\right), 4.73(2 \mathrm{H}$, $\left.17,17^{\prime}-\mathrm{H}\right), 5.08$ (2H, 9,9'-H), 7.0-7.1 (4H, 14,14',16,16'-H).

${ }^{13} \mathrm{C}$ NMR, $\delta_{\mathrm{C}}\left(\mathrm{CDCl}_{3}: \mathrm{CD}_{3} \mathrm{OD}\right): 21.1\left(\mathrm{C}-18,18^{\prime}\right), 26.7\left(\mathrm{C}-3,3^{\prime}\right), 30.2,37.9\left(\mathrm{C}-2,2^{\prime} ; \mathrm{C}-4,4^{\prime}\right), 38.5$ (C-10,10'), 46.0 (C-12,12'), 49.0 (C-8,8'), 71.5 (C-13,13'), 80.3 (C-11,11'), 84.5 (C-9,9'), 100.3 (C-17,17'), 120.5, 128.5 (C-14,14'; C-16,16'), 125.1, 129.6, 135.0, 135.1 (C-5,5'; C-7,7'; C15,15'), $157.0\left(\mathrm{C}-6,6^{\prime}\right), 172.7\left(\mathrm{C}-1,1^{\prime}\right)$. 
${ }^{1} \mathrm{H}$ NMR, $\delta_{\mathrm{H}}\left(\mathrm{C}_{2} \mathrm{D}_{2} \mathrm{Cl}_{4}\right.$, at $\left.393 \mathrm{~K}\right): 1.36\left(\mathrm{~d}, 6 \mathrm{H}, J=5.1 \mathrm{~Hz}, 18,18^{\prime}-\mathrm{H}\right), 1.89\left(\mathrm{~m}, 2 \mathrm{H}, 12,12^{\prime}-\mathrm{H}\right), 1.9-$ $2.1\left(\mathrm{~m}, 6 \mathrm{H}, 3,3^{\prime}-\mathrm{H}_{2}, 10,10^{\prime}-\mathrm{H}_{\mathrm{b}}\right), 2.42\left(\mathrm{~m}, 4 \mathrm{H}, 2,2^{\prime}-\mathrm{H}_{2}\right), 2.6-2.8\left(\mathrm{~m}, 6 \mathrm{H}, 4,4^{\prime}-\mathrm{H}_{2}, 10,10^{\prime}-\mathrm{H}_{\mathrm{a}}\right), 3.17$ $\left(\mathrm{dd}, 2 \mathrm{H}, J=10.8 \mathrm{~Hz}, J=9.8 \mathrm{~Hz}, 8,8^{\prime}-\mathrm{H}\right), 3.41$ (ddd, $2 \mathrm{H}, J=10.8 \mathrm{~Hz}, J=9.8 \mathrm{~Hz}, J=6.1 \mathrm{~Hz}$, $\left.11,11^{\prime}-\mathrm{H}\right), 3.73\left(\mathrm{t}, 2 \mathrm{H}, J=10.8 \mathrm{~Hz}, 13,13^{\prime}-\mathrm{H}_{\mathrm{ax}}\right), 4.46\left(\mathrm{~m}, 2 \mathrm{H}, 13,13^{\prime}-\mathrm{H}_{\mathrm{eq}}\right), 4.75$ (q, $2 \mathrm{H}, J=5.1$ $\left.\mathrm{Hz}, 17,17^{\prime}-\mathrm{H}\right), 5.12$ (m, 2H, 9,9'-H), 7.0-7.2 (m, 4H, 14,14'-H; 16,16'-H).

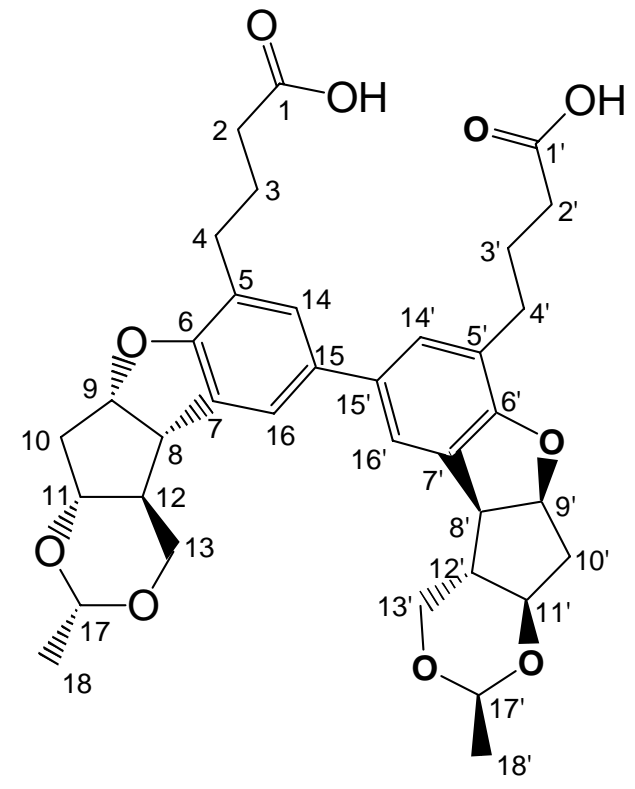

4

(compound is racemic, only one of the two enantiomers is shown)

\section{Structural studies on the dimer}

With the mixture of $\mathrm{CDCl}_{3}: \mathrm{CD}_{3} \mathrm{OD}(1: 1)$ as NMR solvent, due to the possibility of atropisomerism or forming inter- and/or intramolecular hydrogen-bonds, the existence of hindered rotation around the phenyl-phenyl single bond was assumed, when NMR spectra were recorded at different temperatures (from +30 to $-90{ }^{\circ} \mathrm{C}$ ). With deuterated tetrachlorethane as NMR solvent, sharpening of NMR signals was observed at $393 \mathrm{~K}$. So, the dynamic-NMR studies suggested that this molecule appears in more than one conformer at different temperatures with significant activation energies.

At first sight the possibility of atropisomerism emerged around the bond between the two phenyl rings, because of the two large substituents. However, according to the ab-initio calculations of two rotamers (syn isomer is $0 \mathrm{~kJ} / \mathrm{mol}$, anti isomer is $-23.2 \mathrm{~kJ} / \mathrm{mol}$ ) and the two transition states (TS1 is $1.1 \mathrm{~kJ} / \mathrm{mol}$ and TS2 is $0.08 \mathrm{~kJ} / \mathrm{mol}$ ) linking the two rotamers, indicated that these activation energies are negligible at finite temperatures. Further studies reflected another possibility, an internal H-bond occurred between the two carboxylic acids and these connections decrease the energy of molecule to a great extent $(-62.2 \mathrm{~kJ} / \mathrm{mol})$. These calculations were carried 
out in vacuo, therefore in the $\mathrm{CDCl}_{3}: \mathrm{CD}_{3} \mathrm{OD}$ (1:1) solution, which was used as a solvent in the NMR experiments, these energy differences presumably are smaller. This rigid, internal hydrogen-bond increases the activation energy between the two rotamers. The two long alkyl side chains holding the carboxylic acid groups give an opportunity for a large number of conformers, which represent many different states, and cause many different TS between the two rotamers and the conformers. We did not attempt to determine all of the possible conformers, rotamers and TS, but selected states were studied. Only a $10.2 \mathrm{~kJ} / \mathrm{mol}$ energy difference exists between the two chosen rotamers, and two TS were studied which linked these two rotamers. The first TS represents a small activation energy barrier $(6.6 \mathrm{~kJ} / \mathrm{mol})$, however this energy proved to be higher than that for the TS obtained in the case of rotamers without hydrogenbonding. The second TS, in contrast to the first one, is very high in energy $(52.4 \mathrm{~kJ} / \mathrm{mol})$, because of the steric hindrance of the two alkyl chains. These two very different TS assume that many other TS exist in the hypersurface linking the two rotamers and every temperature there is an equilibrium with TS, which has a similar timescale to the NMR spectroscopy. In our opinion this is the reason that the dynamic-NMR measurements show slow equilibrium at every applied temperature. The exact answer to this question requires some ab-initio molecular-dynamic experiments at finite temperature, however this study would overstep the goal of this article.

\section{Acknowledgements}

Authors wish to thank Dr. Judith Halász for the evaluation of the NMR spectra and Dr. Zoltán Mucsi for the ab-initio calculations.

\section{References}

1. Prostaglandins, Leukotrienes and Other Eicosanoids; Marks, F; Fürstenberger,G. Eds; Wiley-VCH: New York, 1999.

2. Drugs of Future 1999, 24, 1258.

3. Wakita, H.; Matsumoto, K.; Yoshiwara H.; Hosono Y.; Hayashi R.; Nishiyama H. Tetrahedron 1999, 55, 2449.

4. Ullmann, F.; Bielecki J. Chem. Ber. 1901, 34, 2174.

5. Bringman, G.; Walter, R.; Weirich, R. Angew. Chem., Int. Ed.. 1990, 29, 977.

6. Fanta P. E. Synthesis 1974, 9.

7. Takagi, K.; Huyama, N.; Sasaki, K. Bull. Chem. Soc. Jpn. 1884, 57, 1887.

8. Calen, I.; Kelsey, D. R. J. Org. Chem. 1986, 51, 2627

9. Vanderesse, R.; Brunet, J.; Caubere, P. J. Organomet. Chem. 1984, 264, 263.

10. Marques, C. A.; Selva, M.; Tundo, P. J. Org. Chem. 1994, 59, 38303.

11. Bamfield, P.; Quan, P. M. Synthesis 1978, 537. 
12. Mukhopadhyay, S.; Ratuer, S.; Spernat, A.; Qafisheh, N.; Sasson, Y. Org. Proc. Res. Dev. 2002, 6, 297

13. Mukhopadhyay, S.; Rothenberg, G.; Wiener, H.; Sasson, Y. Tetrahedron 1999, 55, 14763 